\title{
MATHEMATICS INTERVENTIONS FOR SECONDARY STUDENTS WITH AUTISM SPECTRUM DISORDER: A REVIEW OF RESEARCH QUALITY
}

Jingyuan Zhang, College of Education, Purdue University, zhan3598@purdue.edu

Dr. Mandy Rispoli, College of Education, Purdue University, mrispoli@ purdue.edu

Dr. Yan Ping Xin, College of Education, Purdue University, yxin@ purdue.edu

Mehmet Donat Sulu, College of Education, Purdue University, msulu@ purdue.edu

\begin{abstract}
Including students with autism spectrum disorders (ASD) in K-12 general education is a common practice today. However, there are relatively few mathematics interventions for students with ASD in secondary education. There is also a lack of literature exploring mathematics interventions that reflect grade-level academic requirements and are adapted for students with ASD. The purpose of this paper is to summarize the characteristics of high-quality studies which implemented mathematics interventions for students with ASD in secondary education. Suggestions have also been given for improving the quality of future studies in this field. Twenty-one studies are coded and evaluated according to Council for Exceptional Children (CEC) 2014 standards. Implications for future research and practice are discussed.
\end{abstract}

\section{Results}

Twenty single case design (SCD) studies and one group comparison study were included. The participants included both adolescents with ASD and students with other developmental disabilities (e.g., intellectual disability, language impairment). Articles were evaluated based on whether they met the quality indicators (QI) requirements. The results showed that fourteen studies (67\%) met all CEC quality requirements (Cook et al., 2015). Descriptive statistics of the relevant characteristics were further summarized for those high-quality studies.

\section{Discussion and Implication}

Research quality can be further improved in QI 3.0 intervention agent, QI 5.0 implementation fidelity, QI 6.0 internal validity, and QI 7.0 outcome measures. Additional replications of these highquality SCD studies would be an important next step to improve this field. Replications of SCD studies should consider the participants, settings, and contexts to extend the external validity of these mathematics interventions (Hitchcock et al., 2015). Future research should explore more mathematics skill instructions and interventions according to National Council of Teachers of Mathematics standards. Those efforts will support students with ASD to perform better in mathematics and empower them to achieve more success in the general education environment (Barnett \& Cleary, 2015). We also suggest more studies to include special educators or other schoolteachers to be the interventionist, not the researchers, as they are the final practitioners at school.

\section{References}

Barnett, J. H., \& Cleary, S. (2015). Review of evidence-based mathematics interventions for students with autism spectrum disorders. Education and Training in Autism and Developmental Disabilities, 50(2), 172-185.

Cook, B. G., Buysse, V., Klingner, J., Landrum, T. J., McWilliam, R. A., Tankersley, M., \& Test, D. W. (2015). CEC's standards for classifying the evidence base of practices in special education. Remedial and Special Education, 36(4), 220-234. https://doi.org/10.1177/0741932514557271

Hitchcock, J. H., Kratochwill, T. R., \& Chezan, L. C. (2015). What Works Clearinghouse standards and generalization of single-case design evidence. Journal of Behavioral Education, 24(4), 459-469. https://doi.org/10.1007/s10864-015-9224-1 